Int. J. Electrochem. Sci., 14 (2019) $6722-6736$

\title{
Pb-Ag Alloy Anode Modified with Polyaniline Film and its Electrochemical Performance in Sulfuric Acid Electrolyte
}

\author{
PeiPei $\mathrm{Li}^{1}$, RenChun Fu ${ }^{*}, 1$, Du Jun ${ }^{2}$, Hui Huang ${ }^{2,3}$, ZhongCheng Guo ${ }^{2,3}$ \\ ${ }^{1}$ Department of science, Kunming University of Science and Technology, Kunming 650093, China; \\ ${ }^{2}$ Department of Metallurgy and Energy Engineering, Kunming University of Science and Technology, \\ Kunming 650093, China; \\ ${ }^{3}$ Kun Ming Hendera of Science and Technology Co.,Ltd.,Kunming 650106, China. \\ *E-mail: polymerminer@163.com
}

doi: $10.20964 / 2019.07 .46$

Received: 28 January 2019 / Accepted: 29 March 2019 / Published: 10 June 2019

The nature of the electrode surface plays an important role in the electrode reaction. In this study, $\mathrm{Pb}-$ Ag alloy anodes modified with polyaniline films were prepared by galvanostatic polymerisation. Linear scanning voltammetry (LSV), cyclic voltammetry and potentiodynamic polarisation were measured and compared with those of unprepared $\mathrm{Pb}-\mathrm{Ag}(0.3 \mathrm{wt} \%)$ alloy anodes. The oxygen evolution reaction potential of the modified anodes was lower than that of the unprepared $\mathrm{Pb}-\mathrm{Ag}(0.3 \mathrm{wt} \%)$ anode at same anodic current density. The corrosion resistance of the modified anode was better than that of the unprepared $\mathrm{Pb}-\mathrm{Ag}(0.3 \mathrm{wt} \%)$ anode. SEM images were obtained to characterise the morphology of the polyaniline film, and FTIR spectra confirmed that the film coating the $\mathrm{Pb}-\mathrm{Ag}$ alloy was polyaniline.

Keywords: polyaniline; cyclic voltammetry; linear scanning voltammetry; $\mathrm{Pb}-\mathrm{Ag}$ alloy

\section{FULL TEXT}

(C) 2019 The Authors. Published by ESG (www.electrochemsci.org). This article is an open access article distributed under the terms and conditions of the Creative Commons Attribution license (http://creativecommons.org/licenses/by/4.0/). 